\title{
Exploring the Correlation Between Teacher Pedagogical Content Knowledge and Content Knowledge in Computer Science Classrooms
}

\author{
Tom McKlin \\ The Findings Group \\ Decatur, Georgia USA \\ tom@thefindingsgroup.org \\ Brian Magerko \\ Digital Media Program \\ Georgia Institute of Technology \\ Atlanta, Georgia USA \\ magerko@gatech.edu \\ Emily Bryans \\ The Findings Group \\ Decatur, Georgia USA \\ emily@thefindingsgroup.org
}

\author{
Taneisha Lee \\ The Findings Group \\ Decatur, Georgia USA \\ taneisha@thefindingsgroup.org \\ Doug Edwards \\ Center for Education Integrating \\ Science Mathematics and Computing \\ Georgia Institute of Technology \\ Atlanta, Georgia USA \\ doug.edwards@ceismc.gatech.edu \\ Jason Freeman \\ Center for Music Technology \\ Georgia Institute of Technology \\ Atlanta, Georgia USA \\ jason.freeman@gatech.edu
}

\author{
Dana Wanzer \\ The Findings Group \\ Decatur, Georgia USA \\ dana@thefindingsgroup.org
}

\author{
Sabrina Grossman \\ Center for Education Integrating \\ Science Mathematics and Computing \\ Georgia Institute of Technology \\ Atlanta, Georgia USA \\ sabrina.grossman@ceismc.gatech.edu
}

\begin{abstract}
Educators have long claimed that pedagogical content knowledge (PCK), ways of presenting a subject that make it comprehensible to others, is a critical element of student academic success. This poster presents findings from a preliminary study of Computer Science Principles teachers that demonstrate a significant correlation between teacher PCK and student content knowledge. The study describes the measures used to assess PCK, operationalizes the mechanisms for measuring teacher pedagogical content knowledge, shares the results from a multi-level modeling analysis, and identifies methodological improvements for follow-up research. The findings from this initial study show correlations of teacher PCK with student content knowledge while accounting for other teacher- and student-level variables across multiple schools.
\end{abstract}

\section{KEYWORDS}

Computer science education, pedagogical content knowledge, teacher professional development, STEAM, music, broadening participation

Permission to make digital or hard copies of part or all of this work for personal or classroom use is granted without fee provided that copies are not made or distributed for profit or commercial advantage and that copies bear this notice and the full citation on the first page. Copyrights for third-party components of this work must be honored. For all other uses, contact the Owner/Author.

ITiCSE '19, July 15-17, 2010, Aberdeen, Scotland Uk

(C) 2019 Copyright is held by the owner/author(s)

ACM ISBN 978-1-4503-6301-3/19/07.

https://doi.org/10.1145/3304221.3325556

\section{ACM Reference format:}

Tom McKlin, Taneisha Lee, Dana Wanzer, Brian Magerko, Doug Edwards, Sabrina Grossman, Emily Bryans, and Jason Freeman. 2019. Exploring the Correlation Between Teacher Pedagogical Content Knowledge and Content Knowledge in Computer Science Classrooms. In Proceedings of $24^{\text {th }}$ Annual ACM Conference on Innovation and Technology in Computer Science Education (ITiCSE '19). ACM, New York, NY, USA, 1 page. https://doi.org/10.1145/3304221.3325556

\section{CONTEXT AND PRELIMINARY FINDINGS}

Our preliminary study of 18 teachers and 473 consenting students reveals how teachers identify and address student misconceptions. A multi-level modeling analysis shows a significant relationship between teacher pedagogical content knowledge and student content knowledge. These findings, coupled with the growth in high school computer science and with Hubbard's research on PCK among computer science teachers [1], suggest that professional learning focus on how CS content is understood and misunderstood by students.

\section{ACKNOWLEDGMENTS}

The EarSketch project receives funding from the National Science Foundation (1417835 and 1612644). EarSketch is available online at earsketch.gatech.edu.

\section{REFERENCES}

[1] Hubbard, A. K. (2017). Learning to Teach Computer Science: Qualitative Insights into Secondary Teachers' Pedagogical Content Knowledge. Ph.D Dissertation. Northwestern University. 